\title{
Em memória do Professor José Manuel Mateo Rodríguez (1947-2019)
}

\section{In memory of Professor José Manuel Mateo Rodríguez (1947-2019)}

Lúcio Cunha, Centro de Estudos de Geografia e Ordenamento do Território, Universidade de

Coimbra, Portugal, luciogeo@ci.uc.pt

(1) https://orcid.org/0000-0003-0086-7862

António Vieira, Centro de Estudos de Geografia e Ordenamento do Território, Universidade do Minho, Portugal, vieira@geografia.uminho.pt

(1) https://orcid.org/0000-0001-6807-1153

No passado dia 26 de julho, a Geografia e os geógrafos latino americanos foram surpreendidos pela notícia da morte do geógrafo cubano José Manuel Mateo Rodríguez, professor emérito da Universidade de Havana e ex-presidente da Sociedade Cubana de Geografia.

Possuidor de um carisma natural, era um ser humano simples, de bom trato e extremamente humano. A alegria e o gosto pela vida e pela amizade eram caraterísticas que marcavam a sua personalidade. E reflexo disso é o conjunto infindável de amigos, espalhados por todo o mundo, que sentem agora a sua falta.

Deixa uma vasta obra na área das Geociências e, particularmente, na área da Geografia Física, com destaque para os estudos sobre Geoecologia, Geossistemas, Paisagens, Análise Ambiental e Teoria e Metodologia da Geografia. Ainda que socorrendo-nos de informação necessariamente incompleta e, portanto, manifestamente injusta face ao seu brilho enquanto professor e ao valor da sua qualidade de geógrafo, deixamos algumas notas sobre o seu percurso.

No plano académico, o Professor José Manuel Mateo Rodríguez graduou-se em Geografia pela Universidade de Havana, em 1970, tendo obtido o doutoramento em Ciências Geográficas pela Universidade Estatal de Moscovo no ano de 1979 e, mais tarde, em 2007, concluído também um doutoramento em Ciências na sua Universidade de Havana. Realizou estágios de pós-doutoramento em Análise Ambiental na Universidade de Varsóvia, em 1985, em Geoecologia da Paisagem na Universidade Estatal de Moscovo, em 1988, e em Planeamento Ambiental na Universidade de Munique, em 2010. Era Professor Titular Aposentado da Universidade de Havana, onde era também Professor Emérito, tendo sido nomeado em 22 de março de 2017 pelo Ministro da Educação Superior de Cuba e pelo Reitor da Universidade de Havana. 
Amante confesso da viagem, desde cedo se apaixonou pela Geografia, tendo tido ao longo da sua vida contactos com as Geografias francesa, primeiro, e com as do bloco de Leste (soviética e, depois, russa, polaca, checo-eslovaca e alemã oriental) depois. De seguida voltou-se para a América Latina (Colômbia e México) e, finalmente, interessou-se pelo Brasil, pelas suas paisagens e pelas suas Geografias. Rio Claro, Fortaleza, Presidente Prudente e Ourinhos, Campinas, Teresina, Niterói, Rio de Janeiro, Três Lagoas e Santa Maria foram Universidades que o receberam, onde foi professor convidado, onde proferiu palestras ou onde desenvolveu projectos com colegas brasileiros, quase sempre trabalhando temas teóricos ou aplicados relacionados com o funcionamento dos geossistemas e com a análise da paisagem.

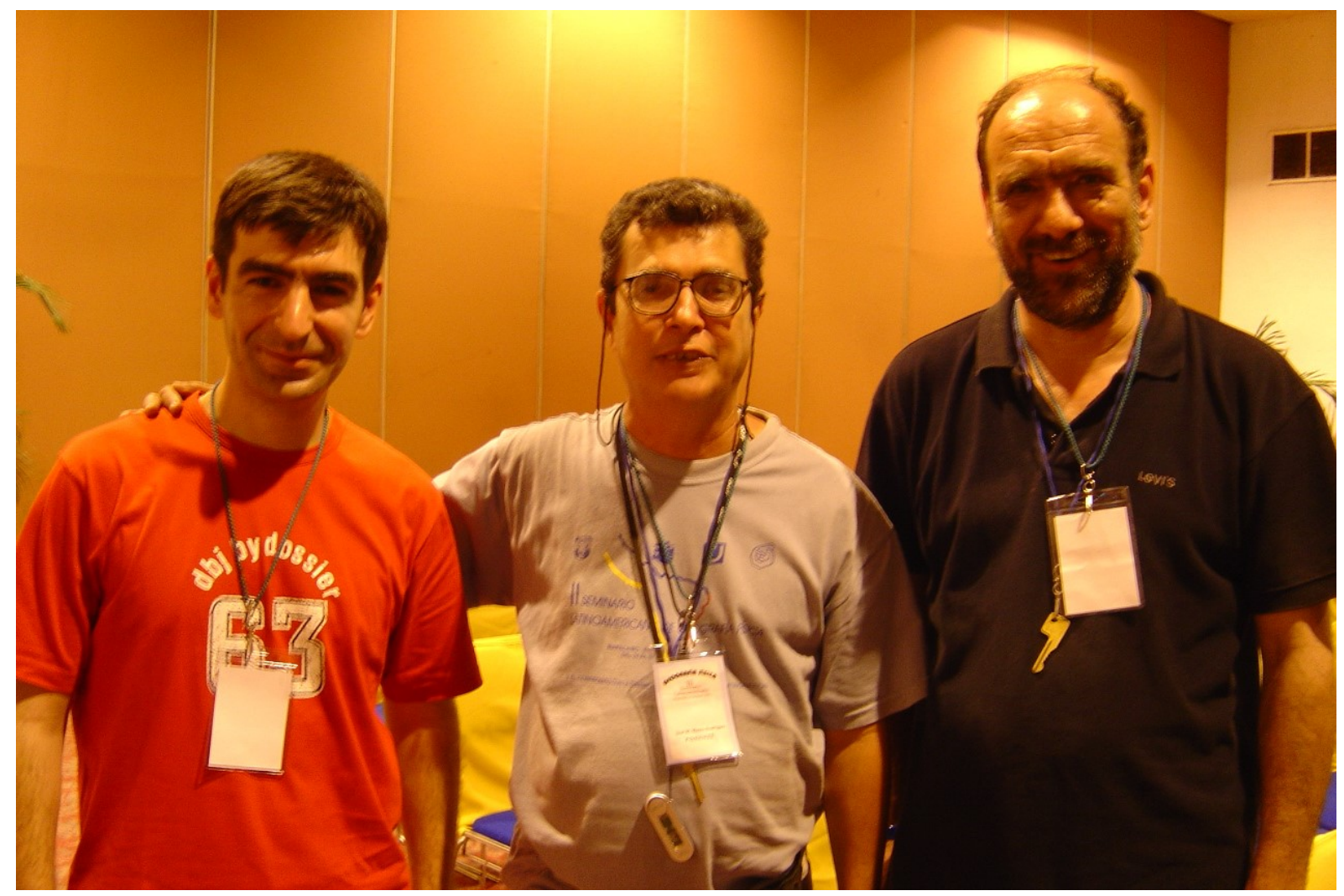

Figura 1: Com o Mateo (ao centro) no III Seminário Latino-americano de Geografia Física em Puerto Vallarta (México), em 2004.

Também desempenhou funções de professor visitante na Universidade de Saragoça, na Universidade Autónoma de Guadalajara, na Universidade de Quintana Roo, na Universidade Nacional de Colômbia, na Universidade dos Andes na Venezuela e na Universidade Nacional Autónoma do México. Foi Presidente da Sociedade Cubana Geografia, de 2010 a 2018. Entre outras homenagens e cargos honoríficos, foi reconhecido com o cargo de Académico Titular de Mérito da Academia de Ciência de Cuba e recebeu o Prémio Nacional de Geografia de Cuba, em 2015, e o Prémio do concurso "Pensar a contra-corrente", em 2018. 
Conhecemos o Professor José Manuel Mateo Rodríguez (entre nós carinhosamente tratado apenas por Mateo) há alguns anos já, no contexto de algumas reuniões científicas realizadas no Brasil e noutros países da América Latina e, sobretudo, dos Seminários Latino-Americanos de Geografia Física (depois alargados ao contexto ibero-americano), reuniões de ciência geográfica e ambiental, mas também de amigos, que o Mateo ajudou a criar, desde o primeiro seminário formal realizado em Havana no ano de 2000, e depois a afirmar até à IX edição realizada no ano de 2016, na portuguesa Universidade do Minho, depois de ter passado pela Venezuela e por Puerto Vallarta (México), Maringá e Santa Maria (Brasil), Coimbra (Portugal), Manaus (Brasil) e Santiago (Chile). Foram sempre reuniões muito concorridas, animadas e produtivas, tanto nos estudos apresentados pelos geógrafos físicos dos diferentes países, como pelos trabalhos de campo e, sobretudo, pelas intensas e produtivas discussões realizadas. Dado o importante papel que desempenhou nestas reuniões e face ao reconhecimento que os seus pares lhe deviam pelo seu carácter, esforço e inteligência, foi nelas por duas vezes homenageado: no VI Seminário Latinoamericano e II Ibero-americano de Geografia Física em Coimbra, Portugal, no ano 2010, homenagem que na altura não pôde receber pessoalmente, dadas algumas tricas burocráticas e políticas que complicaram a emissão do visto que lhe permitiria viajar até Portugal; logo a seguir, também no VII Seminário Latino-americano e III Ibero-Americano de Geografia Física, realizado dois anos depois, em Manaus, onde pôde já estar presente, receber a homenagem e agradecê-la publicamente.

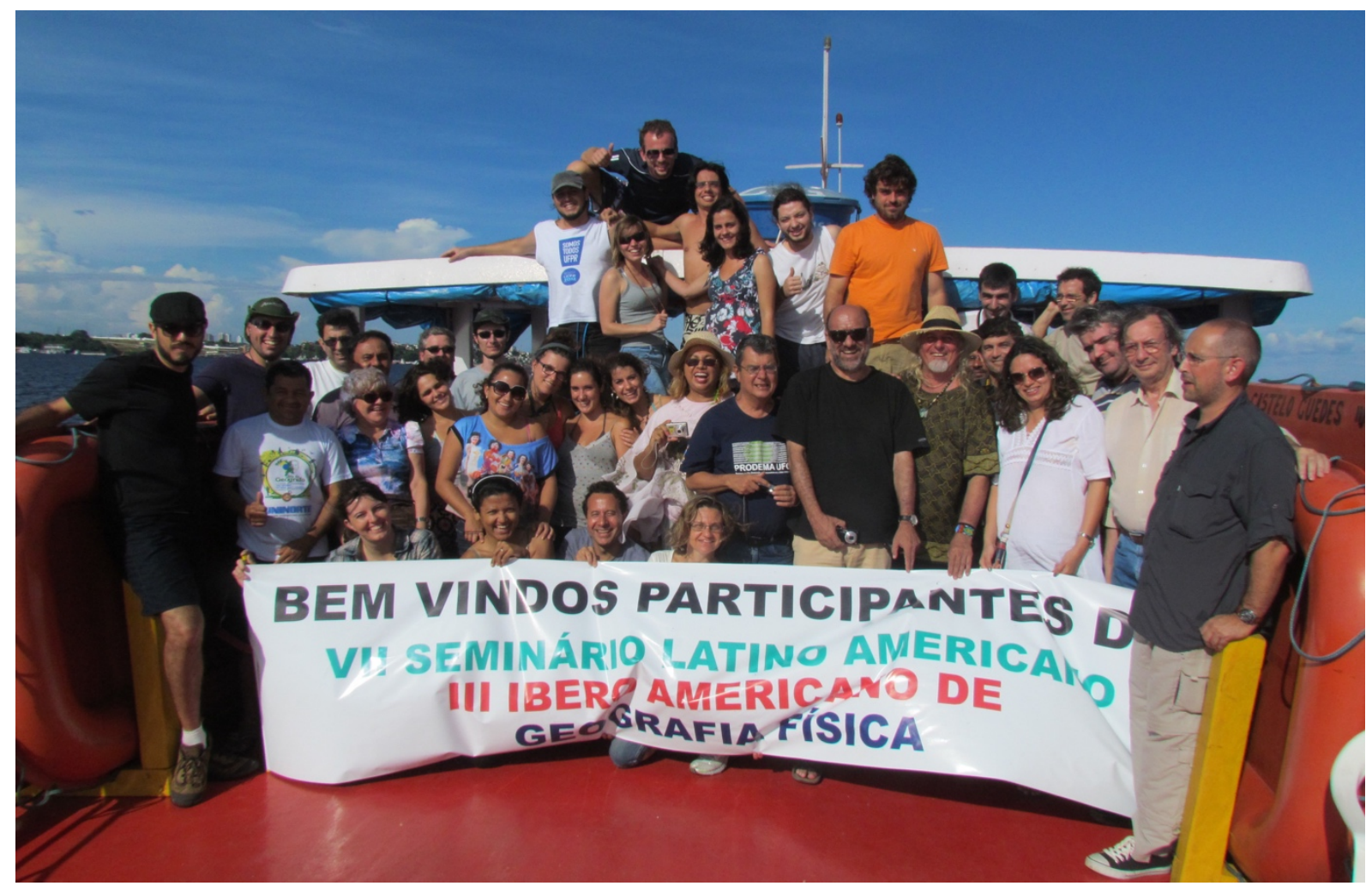

Figura 2: Fotografia de grupo da visita de campo no VII Seminário Latino-americano e III IberoAmericano de Geografia Física, realizado em Manaus, em 2012. 
O pouco que foi já escrito testemunha o mérito do geógrafo e a qualidade do Ser Humano que foi Mateo Rodriguez. Mas que recordamos nós dele? Ao olhar para os livros que escreveu, entre outros, com o seu companheiro de sempre no Brasil, Edson Vicente da Silva, o também nosso Cacau, sobre Geoecologia, Educação Ambiental ou Planeamento e Gestão Ambiental, ao recordarmos as suas apresentações teóricas ou de aplicação e os complexos esquemas conceptuais com que as preenchia, ao percebermos a teoria política (e os preconceitos) de que estão eivados os modelos com que construímos a nossa Geografia, vemos o geógrafo que tinha e transmitia um entusiasmo contagiante pela natureza una e indivisível, pelos geossistemas que a fazem funcionar e pelas paisagens que the dão corpo e visibilidade. Mas, recordamos também o geógrafo que queria uma Natureza e uma Terra ao serviço de todos os Seres Humanos e não apenas ao serviço dos interesses de alguns. Por isso, a par da Geografia rigorosa e bem fundamentada do ponto de vista teórico e metodológico que cultivava, ele sonhava com uma Geografia socialmente comprometida e posta ao serviço do bem-estar de todos.

Basta ler um pouco do que, sobre Geografia Física Integrada, sobre Geossistemas, sobre Paisagem e Ambiente, hoje se publica no Brasil, para sentirmos que a sua influência na Geografia brasileira é, seguramente, muito significativa, indelével e durável. Por isso, por esta enorme perda, estão de luto a Geografia e os geógrafos cubanos, mas estão também de luto a Geografia e os geógrafos brasileiros...

Agostinho da Silva escreveu que "temos, sobretudo, de aprender duas coisas: aprender o extraordinário que é o Mundo e aprender a ser bastante largos por dentro, para o Mundo todo poder entrar...".

Mateo ensinou-nos, e através da sua obra, vai continuar a revelar-nos, as maravilhas do Mundo e o carácter extraordinário e complexo da Natureza que o serve. Nós que, de Portugal, da lbéria e da Europa, de onde escrevemos, tivemos a mesma perda, sentimos a mesma dor, fazemos o mesmo luto, queremos manter o peito e a alma largas para deixar entrar o conhecimento do Mundo, através dos seus ensinamentos, da sua Geografia e do seu exemplo.

Artigo recebido em / Received on: 29/10/2019

Artigo aceite para publicação em / Accepted for publication on: 29/10/2019 